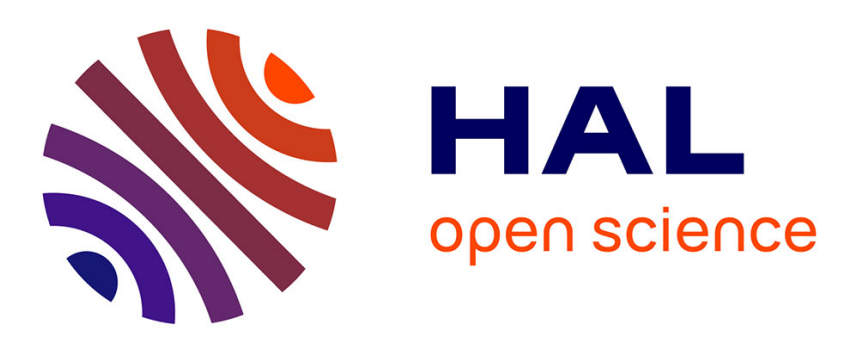

\title{
AUGER AND ELLIPSOMETRIC INVESTIGATION OF THE OXIDATION KINETICS OF SOME METALLIC GLASSES
}

O. Hunderi, R. Bergersen

\section{- To cite this version:}

O. Hunderi, R. Bergersen. AUGER AND ELLIPSOMETRIC INVESTIGATION OF THE OXIDATION KINETICS OF SOME METALLIC GLASSES. Journal de Physique Colloques, 1980, 41 (C8), pp.C8-867-C8-870. 10.1051/jphyscol:19808214 。 jpa-00220320

\section{HAL Id: jpa-00220320 \\ https://hal.science/jpa-00220320}

Submitted on 1 Jan 1980

HAL is a multi-disciplinary open access archive for the deposit and dissemination of scientific research documents, whether they are published or not. The documents may come from teaching and research institutions in France or abroad, or from public or private research centers.
L'archive ouverte pluridisciplinaire HAL, est destinée au dépôt et à la diffusion de documents scientifiques de niveau recherche, publiés ou non, émanant des établissements d'enseignement et de recherche français ou étrangers, des laboratoires publics ou privés. 
Department of Physical Metallurgy, Norwegian Institute of Technology, Trondheim, Norway

Abstract. - The oxidation kinetics of two metallic glasses have been studied by ellipsometry and Auger Electron spectroscopy. We have found that the presence of chromium in Fe based alloys has a marked influence on the thickness of corrosion film formed and on the kinetics of film formation.

\section{INTRODUCTION}

Several authors have reported that amorphous iron based alloys containing more than $8 \%$ chromium exhibit extremely high corrosion resistance in neutral and acid solutions (1). The high corrosion resistance is in part related to the properties of the passive film formed, but mainly determined by the low defect density in the metallic glass surface.

The medium and high temperature atmospheric oxidation of these amorphous alloys has never been studied, and it is the aim of the present investigation to see if the low defect density in the amorphous state has any appreciable influence on the rate and kinetics of atmospheric oxidation

\section{EXPER IMENTAL}

The kinetics of film growth was measured by ellipsometry. With such instrumentation it is possible to observe changes in film thickness less than $0.1 \AA$ when measured in situ and $1-2 \AA$ changes when measured otherwise (2). The amorphous metals used in this investigation were Allied Chemical Metglas 2826 and 2826 A with nominal composition $\mathrm{Fe}_{40^{\mathrm{Ni}}}{ }_{40} \mathrm{P}_{12} \mathrm{~B}_{6}$ and $\mathrm{Fe}_{32}{ }^{\mathrm{Ni}}{ }_{36} \mathrm{Cr}_{14}{ }^{\mathrm{P}} 12^{\mathrm{B}}{ }_{6}$ respectively. The amorphous ribbons were mechanically polished and the ellipsometric parameters $\alpha$ and $B$ immediately measured (3). The samples were then placed in a temperature stabilized furnace and the ellipsometric parameters were again measured after various exposures to the high

temperature atmosphere.

Since the high corrosion resistance of the chromium containing alloy has been attributed to the formation of the oxy-hydroxide we have also studied the corrosion kinetics in a moist atmosphere.

After exposure for 3000 minutes the surface film of a representative selection of samples was studied by Auger electron spectroscopy. Concentration profiles of elements of interest were taken and the approximate composition determined from standard sensitivity factors.

\section{RESULTS}

The thickness of the corrosion film was determined as a function of time at 100, 150, 200 and $250^{\circ} \mathrm{C}$ for the two alloys 2826 and $2826 \mathrm{~A}$. The experimental results are summarized in Figures 1 to 3. Figure 1 shows the thickness of the film on alloy 2826 in dry air against time at the temperatures indicated. Figures 2 and 3 show the corresponding curves for the alloy $2826 \mathrm{~A}$ in dry and moist air respectively.

The kinetics of film growth is not the same for the two alloys. The film thickness on alloy 2826A shows a direct logaithmic growth rate which in a moist atmosphere is transformed into a rather unusual asymptotic growth. The film thickness on alloy 2826 shows piecemeal parabolic growth. This 


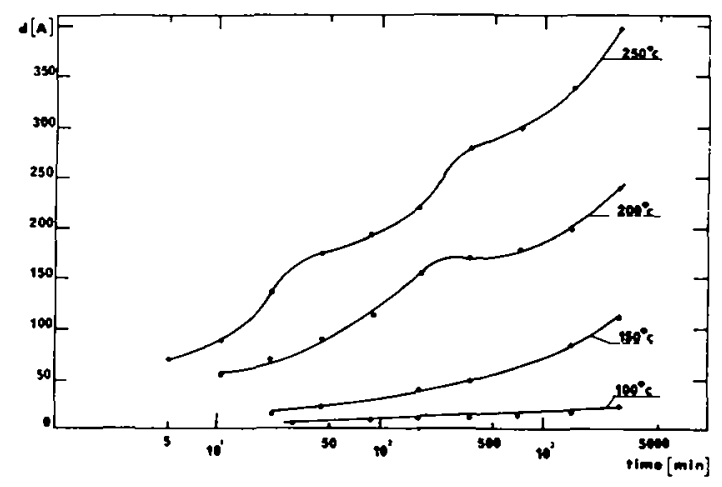

- FIG. 1. Film thickness on alloy 2826 in dry air against time for various temperatures.

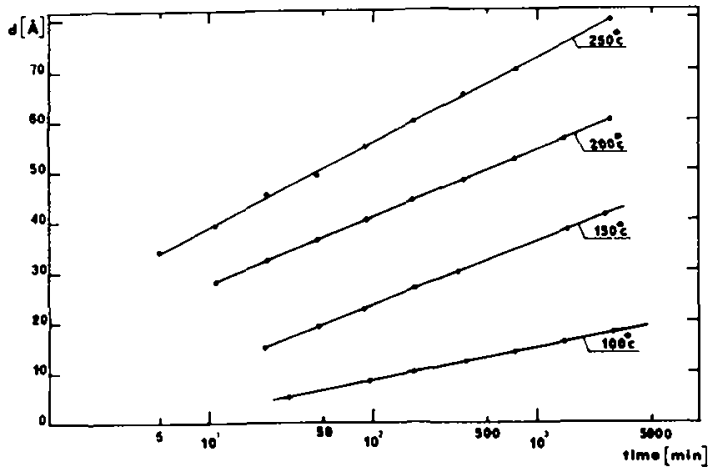

FIG. 2. Film thickness on alloy $2826 \mathrm{~A}$ in dry air against time for various temperatures.

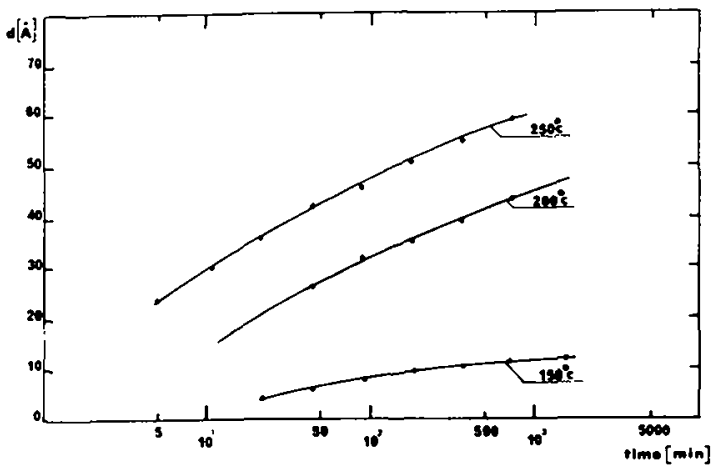

- FIG. 3. Film thickness on alloy $2826 \mathrm{~A}$ in moist air against time for various temperatures. can be demonstrated by plotting the thickness squared against time. Such piecemeal parabolic growth is a well known phenomenon and is caused by surface film fracture. This fracture is found on micrographs of the alloy surface with film. Alloy 2826A shows a homogeneous film, alloy 2826 shows film fracture.

Figures 1 to 3 shows that there is a dramatic difference between the corrosion rate of the two alloys. The addition of chromium has reduced the film thickness by a factor of typically five after 2000 minutes; and most importantly it has changed the kinetics into a slowly growing logarithmic film thickness or into an asymptotic growth.

\section{AUGER PROFILES}

The composition of the corrosion film was studied by Auger electron spectroscopy. After 3000 minutes exposure a representative number of samples were studied in a Varian Automated Auger Spectrometer. Profiles of the elements Fe, Ni, Cr, O, C and $P$ were taken. Some results of this profiling is shown in Figures 4 and 5 . Figure 4 shows the profile in alloy 2826 exposed to dry

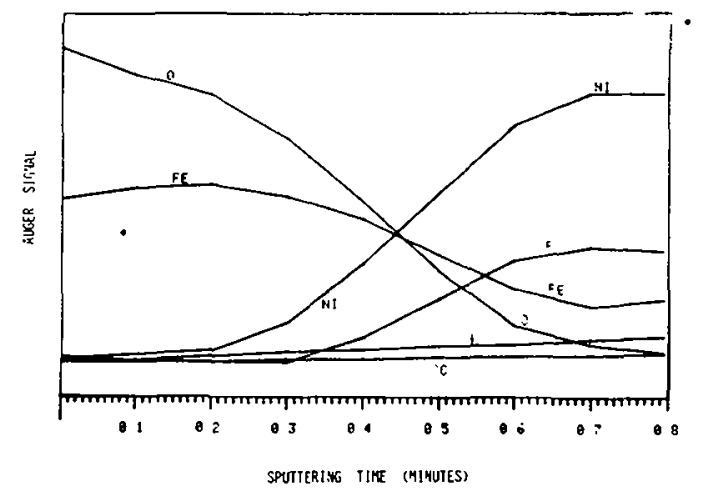

FIG. 4. Auger profiles for alloy 2826 in dry air. 


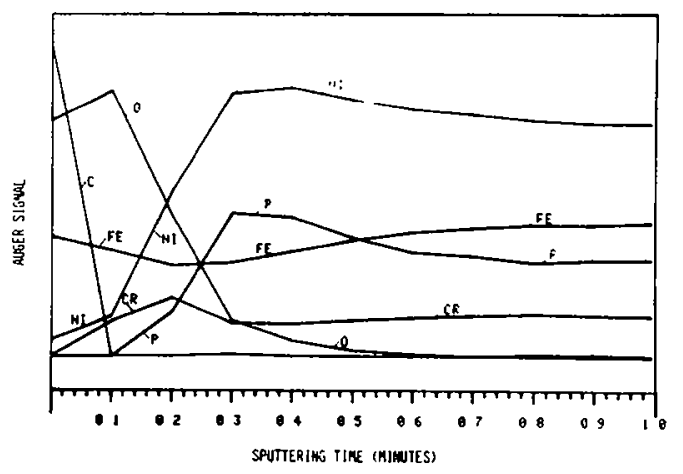

FIG. 5. Auger profiles for alloy $2826 \mathrm{~A}$ in dry air.

air at $150^{\circ} \mathrm{C}$ for 3000 minutes. The sputtering rate was approximately $200 \AA / m i n$. The $\mathrm{film}$ consists mainly of an iron oxide; from the values of the dielectric constant of the film it appears to be the $\mathrm{Fe}_{3} \mathrm{O}_{4}$ phase. This is also consistent with the Auger data using standard sensitivity factors. The profiles are broadened by some $20 \AA$ due to escape depth and knock-on mixing and it is therefore difficult to draw any conclusions as to the sharpness of the interface. By mentally deconvoluting the observed profiles it appears, however, that the $\mathrm{Ni}$ content in the oxide is low.

Figure 5 shows the corresponding profiles for the alloy $2826 \mathrm{~A}$ in dry air. The outher part of the film consists mainly of an iron oxide while the film near the metal is rich in chromium. Unfortunately the broadening of the profile renders a further description of the film composition difficult. From the profiles, in moist air however, it can be seen that the chromium content in the sample exposed to humid atmosphere is higher than in the corresponding film formed in dry air.

\section{DISCUSSION}

The oxidation of alloy $2826 \mathrm{~A}$ in dry air follows a direct logarithmic law

$$
\mathrm{d}=\mathrm{k}_{1} \ln \mathrm{t}+\mathrm{c}_{1}
$$

The rate constant $\mathrm{K}_{1}$ is not strongly temperature dependent - in fact the rate constant hardly shows any change at all from $150^{\circ} \mathrm{C}$ to $200^{\circ} \mathrm{C}$. This is consistent with a model where electron transport via tunneling is rate controlling. This leads, as shown by Mott ${ }^{(4)}$, to a direct logarithmic rate law with the rate constant $K_{1}$ independent of temperature. In our experiments $\mathrm{K}_{1}$ increases from $2.7 \AA$ at $100^{\circ} \mathrm{C}$ to $7.0 \AA$ at $250^{\circ} \mathrm{C}$. Compared to what would be predicted on the basis of a diffusion controlled mechanism with activation energy of say $100 \mathrm{KJ}$, this is for all practical purposes constant is agreement with Motts theory. The alloy $2826 \mathrm{~A}$ in moist air shows an asymptotic growth signifying the formation of a passive protective film.

When plotting the film thickness squared against time for alloy 2826 we find a curve which consists of several linear sections. The film thickness on many metals are found to follow a parabolic time dependence

$$
d^{2}=k_{p} t+C_{p}
$$

As a rule high temperature parabolic oxidation signifies that a thermal diffusion process is rate determining. When plotting the logarithm of the rate constant $K_{p}$ for the first straight section against $1 / T$ we can determine the activation energy. This was done and the activation energy so found was $81 \mathrm{KJ}$. The diffusion constant of $\mathrm{Fe}$ in $\mathrm{Fe}_{3} \mathrm{O}_{4}$ is $180 \mathrm{KJ}$. The observed activation energy is thus lower than the literature values. However, the number of defects in the film is high and the temperature is rather low. The diffusion is therefore predominantly along easy paths and the activation energy for such diffusion is typically half the normal value. 
SUMMARY

The presence of chromium has a marked influence on the oxidation kinetics of Fe based metallic glasses. It prevents surface film fracture and transform the paralinear oxide growth law observed in the chromium free alloy into a logarithmic growth law in dry air and into an asymptotic law in moist air through the formation of a passive oxy-hydroide film near the metal film interface. The temperature independence of the rate constants in the logarithmic law is consistent with the electron tunneing model of Mott while the rate limiting mechanism in the film formation on the chromium free alloy is defect assisted diffusion.

\section{REFERENCES}

1. K. Assami, K. Hashimoto, T. Masumoto and

S. Shimodaira, Corrosion Sci. 12, 909 (1976).

2. J. Kruger, Adv. Electrochem. 9, 227 (1973).

3. 0. Hunderi, Appl. Opt. 16, 3012 (1977).

4. U.R. Evans "The Corrosion and Oxidation of Metals", E. Arnold, London 1960. 